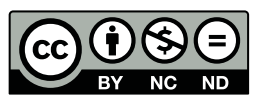

Estudos Teológicos foi licenciado com uma Licença Creative Commons Atribuição - NãoComercial - SemDerivados 3.0 Não Adaptada

http://dx.doi.org/10.22351/et.v58i1.3174

\title{
Ensino Religioso e Capitais CUlturais ${ }^{1}$
}

\author{
Religious Education and Cultural Capitals
}

\section{Péricles Andrade ${ }^{2}$ Ismael de Vasconcelos Ferreira ${ }^{3}$}

\begin{abstract}
Resumo: Este artigo tem como objetivo propor alternativas às dificuldades de implementação de uma agenda multicultural ao Ensino Religioso, sobretudo a partir das tensões entre os capitais culturais religiosos familiares e escolares. Para isso busca responder algumas questões: como é possível aos professores de Ensino Religioso instituir nos espaços escolares princípios multiculturais para estudantes cujos capitais culturais familiares são constituídos por uma linguagem religiosa naturalizada enquanto sistema simbólico com elementos de totalidade coerente e que absolutiza o relativo e o arbitrário? Como propor um Ensino Religioso para crianças e adolescentes com posse de capitais culturais familiares que transfiguram as instituições sociais em sobrenaturais, estruturam suas vidas a partir desses princípios e conferem às relações sociais função simbólica de conferir a ordem social seu caráter transcendente e inquestionável? Partimos do pressuposto de que o conceito de capital cultural de Pierre Bourdieu, aqui também entendido como consciência prévia que tem na religião sua principal fonte de produção de sentido, se constitui num recurso metodológico fundamental enquanto alternativa a resoluções parciais dessas questões.
\end{abstract}

Palavras-chave: Capital cultural. Ensino Religioso. Método. Religião.

Abstract: This article aims to propose alternatives to the difficulties of implementing a multicultural agenda for Religious Education, especially from the tensions between family and school religious cultural capitals. For this, it seeks to answer some questions: How is it possible for teachers of Religious Education to establish multicultural principles in schools for students whose family cultural capitals are constituted by a naturalized religious language as a symbolic system with elements of coherent totality and which absolutizes the relative and the arbitrary? How can we propose Religious

1 O artigo foi recebido em 27 de novembro de 2017 e aprovado em 16 de março de 2018 com base nas avaliações dos pareceristas ad hoc.

2 Doutor em Sociologia pela Universidade Federal de Pernambuco - UFPE, Recife/PE (2006). Professor Associado I do Núcleo de Graduação e do Programa de Pós-Graduação em Ciências da Religião da Universidade Federal de Sergipe - UFS, São Cristóvão/SE, Brasil. Contato: periclesmorais@hotmail.com

3 Doutor em Ciência da Religião pela Universidade Federal de Juiz de Fora - PPCIR-UFJF, em Juiz de Fora/ MG. Atuou como professor substituto do Núcleo de Graduação em Ciências da Religião da Universidade Federal de Sergipe - UFS, em São Cristóvão/SE, Brasil. Contato: ismaelvasconcelos@yahoo.com.br 
Education for children and adolescents with family cultural capitals who transform social institutions into supernatural ones, structure their lives from these principles, and give to social relations a symbolic function of conferring the social order its transcendent and unquestionable character? We start from the assumption that Pierre Bourdieu's concept of cultural capital, here also understood as the prior conscience that has in religion its main source of meaning production, constitutes a fundamental methodological resource as an alternative to partial resolutions of these questions.

Keywords: Cultural capital. Religious Education. Method. Religion.

\section{Introdução}

Em 2017, um desses pesquisadores recebeu um pedido de auxílio através de mensagem enviada pelas redes sociais de um professor da educação básica que atua na Equipe Pedagógica da Secretaria de Educação do Município de Estância, cidade localizada no centro-sul do estado de Sergipe, a $68 \mathrm{~km}$ da capital Aracaju. A questão central abrangia "certa dificuldade em discutir com pais e professores acerca das questões da escola", particularmente "dificuldades para discutir o Ensino Religioso". Naquele momento havia necessidade de "alguém que possa (sic) contribuir neste debate", sobretudo, que tivesse certos capitais culturais. ${ }^{4}$ Por telefone efetivou-se o convite para uma palestra naquela cidade, tematizando o Ensino Religioso (ER), com ênfase nas questões envolvendo o modelo de laicidade no Brasil.

O ER, conforme estabelece a Resolução n ${ }^{\circ}$ 7, de 14 de dezembro de 2010, da Câmara de Educação Básica do Ministério da Educação que fixa Diretrizes Curriculares Nacionais para o Ensino Fundamental, abrange as 9 (nove) séries do ensino fundamental compreendendo a população escolar da faixa etária dos 6 (seis) aos 14 (quatorze) anos de idade, estendendo-se também a todos os que, na idade própria, não tiveram condições de frequentá-lo. Os componentes curriculares obrigatórios do ensino fundamental são assim organizados em relação às áreas de conhecimento: I Linguagens: a) Língua Portuguesa; b) Língua Materna, para populações indígenas; c) Língua Estrangeira moderna; d) Arte; e e) Educação Física; II - Matemática; III Ciências da Natureza; IV - Ciências Humanas: a) História; b) Geografia; V - Ensino Religioso. ${ }^{5}$ Obviamente, as normas relativas ao ER seguem as diretrizes previstas no artigo 33 da Lei de Diretrizes e Bases da Educação n ${ }^{\circ}$ 9.394/96. ${ }^{6}$

Pelo que se observa, o ER abrange estudantes que se encontram na socialização primária, fase inicial por meio da qual a criança se transforma num membro participante da sociedade. Nessa fase, duas instituições sociais participam diretamente

4 BOURDIEU, Pierre; PASSERON, Jean-Claude. A Reprodução: elementos para uma teoria do sistema de ensino. Petrópolis: Vozes, 2008.

5 BRASIL. Resolução $n^{\circ}$ 7, de 14 de dezembro de 2010. Fixa Diretrizes Curriculares Nacionais para o Ensino Fundamental de 9 (nove) anos. Brasília, 14 abr. 2010.

6 BRASIL. Lei n ${ }^{\circ}$ 9.394, de 20 de dezembro de 1996. Estabelece as diretrizes e bases da educação nacional. Brasília, 20 dez. 1996. 
dos processos de aprendizagem: a família e a escola. Através de diversos mecanismos de interação, identificação e interiorização, as crianças e adolescentes adquirem os significados socialmente reconhecidos da linguagem, aprendem as atitudes "corretas", a "tomar as atitudes do outro" e interiorizam os comandos e proibições de ordem moral vindos do exterior. É o nascimento da consciência. ${ }^{7}$ Adquirem também identidades sociais e autoidentidades, séries incontáveis de processos por meio dos quais aprendem, compartilham, criam e reproduzem ação, pensamento e comunicação, que possibilitam não apenas a sua introdução passiva no mundo, mas também a constituição de um mundo no qual passam a habitar e simultaneamente desenvolvem suas individualidades.

Ao mesmo tempo em que as crianças se apropriam subjetivamente do mundo social, apropriam-se subjetivamente de sua própria identidade, que se constrói em relação com esse mundo. São processos que perpassam toda a infância de diversas maneiras e não um marco temporal no qual as crianças são repentinamente inseridas no mundo. Além da família, atribui-se à escola a função primordial de socializar a criança. Essa instituição é incumbida de iniciar a criança egressa do universo familiar na vida social adulta. Os pais enviam seus filhos à escola para que a mesma promova a sua integração à sociedade, o que faz com que a educação escolar desempenhe funções além da sua alçada. Porém, ao entrar para a escola, a criança já é um ser socializado. A criança não é um ser despregado da sociedade em que vive, pois desde a sua concepção já tem uma existência social e, ao nascer, se coloca em relação com o sistema social em que irá viver. Sua própria existência já é uma atividade social e que, por conseguinte, é um ser social, é um ser genérico. ${ }^{8}$

Distante de se constituir enquanto um espaço de mera transmissão de conhecimento, a escola também é um espaço de socialização de cultura, mais precisamente de culturas escolares. Essas se constituem em conjuntos de normas que definem conhecimentos a ensinar e condutas a inculcar, além de práticas que permitem a transmissão desses conhecimentos e a incorporação de comportamentos. Para além dos limites da escola, pode-se buscar identificar modos de pensar e agir largamente difundidos no interior de nossas sociedades, modos que não concebem a aquisição de conhecimentos e habilidades senão por intermédio de processos formais de escolarização.

A cultura escolar compreende também as culturas infantis, que se desenvolvem nos pátios de recreio e o afastamento que apresentam em relação às culturas familiares. Essa é efetivamente uma cultura conforme e seria necessário definir, a cada período, os limites que traçam a fronteira do possível e do impossível.

O estudo histórico das disciplinas escolares mostra que, diante das disposições gerais atribuídas pela sociedade à escola, os professores dispõem de uma ampla liber-

7 BERGER, Peter; BERGER, Brigitte. Socialização: como ser um membro da sociedade. In: FORACCHI, Marialice Mencarini; MARTINS, José de Souza. Sociologia e Sociedade: leitura de introdução à Sociologia. Rio de Janeiro: Editora LTC, 1980. p. 200-214.

8 GRIGOROWITSCHS, Tamara. O Conceito "Socialização" caiu em desuso? Uma análise dos processos de socialização na infância com base em Georg Simmel e George H. Mead. Educação e Sociedade, Campinas, v. 29, n. 102, p. 33-54, jan./abr. 2008. 
dade de manobra: a escola não é o lugar da rotina e da coação e o professor não é o agente de uma didática que lhe seria imposta de fora. Mesmo se a corporação à qual pertence exerce uma pressão, ele sempre tem a possibilidade de questionar a natureza de seu ensino, sendo a liberdade evidentemente muito maior nas margens do sistema.

De fato, a única restrição exercida sobre o professor é o grupo de alunos que tem diante de si, isto é, os saberes que "funcionam" e os que "não funcionam" diante desse público. Convém examinar atentamente a evolução das disciplinas escolares, levando em conta diversos elementos que, em ordem de importância variada, compõem esta estranha alquimia: os conteúdos ensinados, os exercícios, as práticas de motivação e de estimulação dos alunos, que fazem parte dessas "inovações" que não são vistas, as provas de natureza quantitativa que asseguram o controle das aquisições. ${ }^{9}$

A emergência de culturas escolares pautadas em agendas multiculturais se evidencia em sociedades cada vez mais plurais do ponto de vista religioso, tal como na sociedade brasileira. Esses processos vinculam-se diretamente aos desafios postos pelas mudanças implementadas com a Lei $\mathrm{n}^{\circ}$ 9.475/1997, que deu nova redação ao artigo 33 da Lei n ${ }^{\circ} 9.394$, de 20 de dezembro de 1996, que estabeleceu as diretrizes e bases da educação nacional. ${ }^{10}$

Apesar de este artigo ter sido tão explorado por pesquisadores e professores do ER, ressaltamos algumas questões basilares dessa pesquisa: 1) o Art. 33 indica que está vedada qualquer forma de proselitismo, prevalecendo o respeito à diversidade cultural religiosa no Brasil; 2) o ER passa a ser entendido e definido como integrante da formação básica do cidadão (o que afeta diretamente a questão do direito à diferença e à liberdade); 3) passa a incumbência de cada sistema de ensino regulamentar os procedimentos para a definição dos conteúdos e estabelecimento das normas para a habilitação e admissão dos professores, indicando uma descentralização do processo e abrindo uma brecha para que cada estado possa legislar de forma autônoma; 4) indica que cabe à entidade civil, constituída pelas diferentes denominações religiosas, a definição dos conteúdos a serem ministrados em sala de aula. Na própria Resolução $\mathrm{n}^{\circ} 7$, de 14 de dezembro de 2010, esses sentidos estão postos no parágrafo único do artigo $4^{\circ}$ :

As escolas que ministram esse ensino deverão trabalhar considerando essa etapa da educação como aquela capaz de assegurar a cada um e a todos o acesso ao conhecimento e aos elementos da cultura imprescindíveis para o seu desenvolvimento pessoal e para a vida em sociedade, assim como os benefícios de uma formação comum, independentemente da grande diversidade da população escolar e das demandas sociais ${ }^{11}$.

Ainda no artigo $5^{\circ}$ dessa Resolução, destaca-se que a educação desenvolve o potencial humano, "o exercício dos direitos civis, políticos, sociais e do direito à diferença, sendo ela mesma também um direito social, e possibilita a formação cidadã e o

9 JÚLIA, Dominique. A cultura escolar como objeto histórico. Revista Brasileira de História da Educação, n. 1, p. 9-43, jan./jun. 2001.

${ }^{10}$ BRASIL, 1996.

11 BRASIL, 2010. 
usufruto dos bens sociais e culturais". Nesse mesmo artigo, no parágrafo 4, evidencia-se atenção às desigualdades quanto ao acesso e àquelas historicamente produzidas. Dentre os princípios éticos previstos em seu artigo $6^{\circ}$, também se destaca o combate e eliminação de quaisquer manifestações de preconceito de origem, raça, sexo, cor, idade e quaisquer outras formas de discriminação. ${ }^{12}$

Nesse sentido, a escola tem um papel significativo na mudança de mentalidade, superação dos preconceitos e combate às atitudes discriminatórias. Em primeiro lugar, por ser o espaço que deve ser constituído a partir da convivência de estudantes com capitais culturais diferenciados, sobretudo os religiosos. Em segundo, por também se constituir num lugar onde são ensinadas as regras dos espaços públicos para o convívio democrático com a diferença. Por fim, a escola apresenta às crianças conhecimentos sistematizados sobre a realidade plural das sociedades. ${ }^{13}$

Diante dessa problemática vivenciada e apresentada, este artigo tem como objetivo propor alternativas às implicações e dificuldades de implementação de uma agenda multicultural ao ER. Como recurso metodológico será adotado o conceito de capital cultural conforme elaborado no âmbito do conhecimento praxiológico de Pierre Bourdieu como um recurso basilar para aqueles que atuam no ER, articulando-o ao conceito de cultura escolar de Dominique Júlia e de uma discussão mais epistemológica de religião a partir de uma teoria que fundamenta a perspectiva fenomenológica das Ciências da Religião, tendo em conta sínteses teóricas de autores cujos trabalhos referenciam essa área nesta temática.

\section{Dilemas epistemológicos do Ensino Religioso}

Mesmo constando na base nacional comum desde 2010, o Ministério da Educação (MEC) não estabeleceu parâmetros curriculares nacionais para o ER, desconsiderando o conhecido documento ${ }^{14}$ elaborado pelo Fórum Nacional Permanente do Ensino Religioso (FONAPER), que ampliou a definição das "aulas de religião", outrora sob a tutela dos religiosos, mas mantendo uma perspectiva do "transcendente" como abordagem para a disciplina. Como consequência, essa desregulamentação impede que o sistema federal de ensino defina o processo de formação docente, atribuição essa dos conselhos estaduais e municipais. ${ }^{15}$

Isso acarretou uma situação conturbada, pois permitiu que as unidades de ensino construíssem currículos interessados em demandas específicas, abrindo flancos ou brechas para que estados e municípios não formulassem currículos, materiais pedagógicos e promovessem a habilitação de educadores. O caráter facultativo da matrícula, outro ponto dissonante, é interpretado como justificativa para não oferta do ER, quan-

12 BRASIL, 2010.

${ }^{13}$ RODRIGUES, Elisa. Formação de professores para o ensino de religião nas escolas: dilemas e perspectivas. Ciências da Religião: história e sociedade, São Paulo, v. 13, n. 2, p. 19-46, jul./dez. 2015.

${ }^{14}$ Parâmetros Curriculares Nacionais - Ensino Religioso, publicado em 2009.

${ }_{15}$ PAULY, Evaldo Luis. O dilema epistemológico do ensino religioso. Revista Brasileira de Educação, $\mathrm{n}$. 27, p. 172-212, set./out./nov./dez. 2004. 
do a matrícula nesse componente curricular é um direito dos estudantes assegurado por lei. Somam-se ainda justificativas de certa leitura do caráter laico do Estado, do sentido privado da religião, da falta de infraestrutura, carga horária, professores habilitados e do que e como ensinar. ${ }^{16}$

Esses novos sentidos do campo religioso brasileiro constituíram mudanças ao longo dos vinte anos da vigência da Lei ${ }^{\circ}$ 9.475/1997. De certo modo, apesar dos seus significativos limites de implementação, ela reduziu ou acabou legalmente com a possibilidade das denominações religiosas controlarem o ER na esfera pública. ${ }^{17}$

Com isso, ao longo de duas décadas, constatou-se no campo educacional a instituição de três macromodelos no ER. Em primeiro, o interconfessional, vigente em estados como Rio Grande do Sul, Santa Catarina, Paraná, Espírito Santo, Pernambuco, Alagoas, Piauí, Pará, Amapá e Sergipe, é o que procura conciliar um grupo de religiões. As aulas tratam das doutrinas, valores e símbolos comuns à matriz cristã em uma perspectiva ecumênica. Em segundo lugar, o modelo confessional, tradicionalmente católico, foi adaptado para contemplar um caráter multirreligioso nos estados do Rio de Janeiro, Bahia, Ceará e Acre. Nesse modelo os alunos são divididos de acordo com suas crenças e cada professor trabalha as noções de sagrado das religiões representadas. $\mathrm{O}$ governo contrata os profissionais indicados pelas entidades religiosas que são responsáveis pela formação dos professores e por seu acompanhamento. Por fim, há o modelo histórico, que aborda a religião como fenômeno social e que tem na história sua objetividade, tendo como exemplo basilar de aplicação o estado de São Paulo. Com formação universitária nessa área, o professor seria capaz de apresentar aos alunos os diversos fenômenos religiosos e conceitos do sagrado sob a perspectiva de sua interação com a história. ${ }^{18}$ Os cursos de Ciências da Religião seguem essa perspectiva e corroboram o caráter não proselitista do ER, analisando a religião como um fenômeno.

Essas mudanças, articuladas com os anseios mais amplos de uma agenda multicultural, também promoveram a formação dos professores dessa matéria de ensino. Em geral, o ER é ministrado por agentes com diversas graduações (até mesmo com cursos de nível médio) ou com formação complementar gerida por instituições religiosas, sobretudo pelas igrejas cristãs em parceria com os sistemas públicos de ensino. Tais questões envolvem diretamente as tensões envolvendo o ER no Brasil, pois se antes o espaço escolar era constituído apenas pelas disputas entre os agentes vinculados diretamente ao campo religioso, com credenciais das denominações religiosas a partir da posse de capitais culturais católicos e evangélicos, atualmente novos agentes se apresentam nas "arenas escolares". As tensões que antes se verificavam entre professores com vínculos confessionais foram ampliadas a partir da constituição de uma política educacional de formação de professores do ER conforme as diretrizes da

${ }^{16}$ RODRIGUES, 2015.

17 PAULY, 2004.

${ }^{18}$ LUI, Janayna de Alencar. Educação, laicidade e religião: controvérsias sobre a implementação do ensino religioso em escolas públicas. Tese (Doutorado em Sociologia e Antropologia) - Instituto de Filosofia e Ciências Sociais da Universidade Federal do Rio de Janeiro (IFCS-UFRJ), 2011. 
Lei n ${ }^{\circ}$ 9.475/1997, sobretudo com a emergência dos cursos de graduação em Ciências da Religião com habilitação em Licenciatura em Ensino Religioso, conforme destaca Elisa Rodrigues:

Nas licenciaturas em Ciência(s) da Religião, essa direção tem sido tomada desde 2006, quando professores e pesquisadores de religião ligados a essa área assumiram o lugar de formadores de professores(as) para o ER. Pode-se dizer que esse encaminhamento, fruto de um desenvolvimento histórico que teve início ainda nos anos 1970, mas que se autonomizou das igrejas marcadamente em 1996 (cf. SOARES, 2009), deu-se em função do reconhecimento da Ciência(s) da Religião como área capaz de fornecer o instrumental teórico e metodológico adequado para o estudo e o ensino do fato/fenômeno religioso. Além disso, essa área tem se mostrado interessada na discussão de parâmetros epistemológicos que construam um ensino da religião nas escolas afinado com nossas atuais necessidades históricas e demandas por educadores(as) qualificados. É intento dessas licenciaturas o reforço e a consolidação do processo de construção de um Estado pluralista e uma sociedade civil capaz de enfrentar os desafios das diversidades, sejam elas religiosas, de gênero, étnicas ou culturais ${ }^{19}$.

De certo modo, há um consenso social quanto ao conhecimento sobre as tradições religiosas enquanto parte do patrimônio imaterial, discurso de sentido e códigos de usos e costumes que têm efeitos sobre as condutas de pessoas religiosas. Mesmo entre os não religiosos o entendimento sobre o que pensam, dizem e fazem as pessoas religiosas constitui importante instrumento para o debate sobre direitos e deveres na esfera pública. Nesse sentido, a formação docente para o ER deve levar em conta as linguagens da religião e seus campos de sentido, assim como as possibilidades de construção de pontes que facilitarão o diálogo entre cidadãos religiosos e não religiosos, fomentando uma cultura de reconhecimento, respeito pela alteridade e cidadania. ${ }^{20}$

Embora o pluralismo religioso no Brasil não seja uma novidade, a forma pela qual ele se constituiu no passado, sobretudo em confronto com um modelo de ER claramente subordinado à hegemonia católica, indica que houve nos últimos anos uma significativa mudança na relação entre seus componentes e também nas pretensões dos diferentes grupos em relação à educação. Cada vez mais são postos aos educadores desafios na desconstrução e reconhecimento do caráter desigual e discriminador da educação. Por exemplo, o questionamento do caráter monocultural e etnocêntrico que, explícita ou implicitamente está presente na escola e nas políticas educativas e impregnam os currículos escolares; e a necessidade de articular igualdade e diferença, através do reconhecimento e da valorização da diversidade cultural, com questões relativas à igualdade e ao direito à educação. ${ }^{21}$ Isso vem impondo à dinâmica edu-

${ }^{19}$ RODRIGUES, 2015, p. 42.

${ }^{20}$ RODRIGUES, 2015.

${ }^{21}$ GONÇALVES, Luiz Alberto Oliveira; SILVA, Petronilha Beatriz Gonçalves e. Multiculturalismo e educação: do protesto de rua a propostas e políticas. Educação e Pesquisa, São Paulo, v. 29, n. 1, p. 109-123, jan./jun. 2003. 
cacional o estabelecimento de uma epistemologia para o ER que lhe traga uma especificidade enquanto matéria de ensino, algo já bastante discutido e com resultados muito profícuos, notadamente nos âmbitos de discussão do ER (como FONAPER, grupos de trabalho de associações ligadas a programas de pós-graduação em Teologia e Ciências da Religião e universidades que vêm estimulando pesquisas stricto sensu na temática).

\section{Capitais culturais religiosos}

Na esteira da discussão epistemológica para o ER partimos do pressuposto que o conceito de capital cultural, de Pierre Bourdieu, se constitui num recurso fundamental enquanto auxílio teórico e metodológico à abordagem pedagógica dos professores da disciplina. Esse conceito está no âmbito da leitura bourdieusiana dos fenômenos educacionais que, juntamente com Jean-Claude Passeron, a partir da década de 1960, formularam uma resposta original e abrangente para o problema das desigualdades escolares. $^{22}$

Até meados do século XX predominava nas Ciências Sociais e no senso comum uma visão extremamente otimista que atribuía à escolarização um papel central no duplo processo de superação do atraso econômico, do autoritarismo e dos privilégios. Havia uma crença de que o problema do acesso à educação seria resolvido por meio da escola pública e gratuita, o que garantiria a igualdade de oportunidades entre todos os cidadãos. Nessa perspectiva, ainda vigente em alguns espaços sociais, acredita-se que os indivíduos competem dentro do sistema de ensino em condições iguais e aqueles que se destacam conseguem êxito por seus dons individuais. Assim, por uma questão de justiça, os vencedores nas disputas educacionais deveriam "naturalmente" ocupar as posições sociais superiores na hierarquia social.

Mas, ao contrário dessa ótica, estabeleceram-se questões práticas, tais como: o desempenho escolar depende exclusivamente dos indivíduos? Os alunos competem no espaço escolar com as mesmas chances? Não são negados os dons individuais? Com esses questionamentos evidencia-se um esforço em demonstrar que o desempenho escolar também está associado à origem social dos alunos. Traços como classe, etnia, gênero, local de moradia, entre outros, podem influenciar no sucesso ou fracasso dos discentes.

Num artigo intitulado "A Escola conservadora: as desigualdades frente à escola e à cultura", Bourdieu ${ }^{23}$ questiona o mito da "escola libertadora" ao demonstrar que, ao contrário do que se propaga, observa-se no sistema escolar francês um dos fatores mais eficazes de conservação social, pois fornece a aparência de legitimidade às desigualdades sociais e sanciona a herança cultural e o dom social tratando como natural. ${ }^{24}$

${ }^{22}$ BOURDIEU; PASSERON, 2008.

${ }^{23}$ BOURDIEU, Pierre. A Escola conservadora: as desigualdades frente à escola e à cultura. In: NOGUEIRA, Maria Alice; CATANI, Afrânio. Escritos de Educação: Pierre Bourdieu. 3. ed. Petrópolis: Vozes, 2001.

${ }^{24}$ BOURDIEU; PASSERON, 2008. 
É perceptível que nessa leitura a educação perca o papel que lhe fora atribuído de instância transformadora e democratizadora da sociedade e passe a ser vista como uma das principais instituições por meio da qual se mantêm e se legitimam os privilégios sociais. Nessa perspectiva educacional pode-se identificar algumas teses. Como é constatado, os alunos não são indivíduos abstratos que competem em condições relativamente igualitárias na escola. Ao contrário, esses se constituem em atores socialmente constituídos que trazem uma bagagem social e cultural diferenciada. Os gostos mais íntimos, as preferências, as aptidões, as posturas corporais, a entonação de voz, as aspirações relativas ao futuro profissional, tudo seria socialmente constituído. Nisso, constata-se que o agente da educação é caracterizado por uma bagagem socialmente herdada e que a partir dessa ótica a escola não seria uma instituição neutra na transmissão da cultura e na avaliação dos alunos. Pelo contrário, ela reproduz e legitima as dominações e violências simbólicas ignorando, no âmbito dos conteúdos de ensino que transmite, dos métodos e técnicas de transmissão e dos critérios de avaliação, as desigualdades culturais entre as crianças. Ao tratar formalmente de modo igual em direitos e deveres quem é diferente, a escola privilegiaria quem, por sua bagagem familiar, já é privilegiado. As críticas de Bourdieu indicam que se a igualdade educativa alardeada pelas decisões oficiais não progride é porque os discursos são mistificadores e tanto a sociedade como o Estado não querem realmente a democratização.

Nessa ótica a compreensão do funcionamento da escola aponta que as diferenças nos resultados escolares dos alunos tenderiam a ser vistas como diferenças de capacidade (dons desiguais) enquanto que, na realidade, decorreriam da maior ou menor proximidade entre a cultura escolar e a cultura familiar do aluno. Os alunos que dominam, por sua origem social, os códigos necessários à decodificação e assimilação da cultura escolar e que, em função disso, tenderiam a alcançar o sucesso escolar, seriam aqueles pertencentes às classes dominantes. A legitimação das desigualdades sociais ocorreria, por sua vez, indiretamente, pela negação do privilégio cultural dissimuladamente oferecido aos filhos das classes dominantes. ${ }^{25}$

$\mathrm{O}$ grau variado de sucesso alcançado pelos alunos pode ser explicado por sua origem social que os colocaria em condições mais ou menos favoráveis diante das exigências escolares. Nessa linha de raciocínio, o capital cultural constitui o elemento da bagagem familiar que teria o maior impacto na definição do destino escolar. A posse ou não de um capital cultural específico pode favorecer o desempenho escolar na medida em que facilitaria a aprendizagem dos conteúdos e códigos escolares. As referências culturais, os conhecimentos considerados legítimos e o domínio maior ou menor da língua culta, trazidos do berço familiar, por exemplo, facilitam o aprendizado escolar na medida em que funcionaria como uma ponte entre o mundo familiar e a cultura escolar. É o nível cultural global do grupo familiar que mantém a relação mais estreita com o êxito da criança. Aquelas oriundas das classes menos favorecidas herdam os hábitos e os treinamentos. Também herdam saberes, "gostos" e "bons

${ }^{25}$ BOURDIEU; PASSERON, 2008. 
gostos", cuja rentabilidade escolar é tanto maior quanto mais frequentemente esses imponderáveis da atitude são atribuídos ao dom. ${ }^{26}$

As crianças oriundas de espaços socialmente favorecidos veriam a escola como uma continuação da socialização primária. Desse modo, as crianças cujas famílias dispõem de recursos econômicos transferidos para aquisição de computadores teriam, por exemplo, maior facilidade com os novos recursos adotados em sala de aula. Contrariamente, os alunos oriundos de famílias desfavorecidas economicamente teriam mais dificuldades quanto à aprendizagem dos conteúdos e códigos escolares. A avaliação dos alunos vai muito além de uma simples verificação da aprendizagem, incluindo um verdadeiro julgamento cultural e até mesmo moral dos alunos. Esses são cobrados em relação ao estilo elegante de falar, de escrever e até mesmo de se comportar. Tais exigências só podem ser plenamente atendidas por quem foi previamente socializado nesses mesmos valores. Como diria Bourdieu, a esperança subjetiva de êxito próprio é violentada simbolicamente pelas oportunidades objetivas disponibilizadas para aquela classe ou categoria. Toda ação pedagógica que serve à seleção técnica e social é uma violência simbólica. Exerce um poder de um arbitrário cultural. ${ }^{27}$

Essas teses podem se relacionar diretamente ao ER. Embora essa matéria de ensino não contenha avaliações que impliquem certames entre estudantes e não implique questões relativas ao sucesso ou fracasso escolar, há uma tensão entre o capital escolar contido no conteúdo ministrado pelos professores e os capitais religiosos dos estudantes, sobretudo aqueles de matrizes não cristãs.

Diante da crítica ao papel normatizador da escola que intenta instituir conteúdos e valores a serem implementados na vida dos alunos, algo visto como muito positivo pela própria sociedade hodierna, a religião ainda é posta como algo privado, de caráter pessoal e, portanto, de atribuição da família, uma herança cultural das leis que outrora regulamentavam a educação e o ER. Até na LDB nº 9.394/96 estava implícita uma responsabilidade exclusiva da família do educando no tratamento da sua educação religiosa. Esse dispositivo foi atualizado pela lei $n^{\circ} 9.475 / 97$, que alterou o artigo 33, vedando quaisquer formas de proselitismo, ou seja, de confessionalização na escola pública, e atribuindo aos sistemas de ensino o estabelecimento de conteúdos para a disciplina. ${ }^{28}$

Contudo, tal abordagem desconsidera o caráter eminentemente constitutivo e profundo que tem a religião nas dinâmicas sociais que a escola julga ter precedência teórica e formativa. Veja-se primeiramente a religião institucional, ainda bastante presente, sobretudo nas comunidades onde as escolas públicas atuam. Como já discutido, os alunos chegam ao ambiente escolar impregnados de capitais culturais, dentre eles a religião formal (institucional) que lhes é intrínseca, e por meio dela interagem com o meio em que se encontram. Em seguida, e bem mais eloquente, existe o indivíduo religioso que, munido da potencialidade da religião, agora em uma perspectiva onto-

\footnotetext{
${ }^{26}$ BOURDIEU; PASSERON, 2008.

27 BOURDIEU; PASSERON, 2008.

${ }^{28}$ BRASIL, 1996.
} 
lógica e bem menos institucional, interage de maneira mais radical a partir daquilo que lhe constituiu um sentido último para sua existência.

A metáfora da "arena religiosa" se concretiza quando não há previsibilidade daquilo que já se pensou para a escola em ser um espaço de "aceitação do novo e rejeição a qualquer forma de discriminação" 29 . Ora, à medida que conteúdos que envolvem a resolução de problemas são administrados unilateralmente ou, como explora o senso comum, atentando exclusivamente para o interesse da maioria, torna-se problemático lidar com o diferente, com alguém fora de padrões e estereótipos estabelecidos socialmente ou, de maneira mais objetiva, com pessoas que comungam de pensamentos religiosos divergentes. Com isso, a escola cede seu espaço de promovedora de diálogo, portanto contempladora dos mais diversos capitais culturais, para favorecer uma militância que, ainda que divulgue um discurso progressista, como em alguns casos, facilita a sujeição e perseguição aos que se encontram fora desses consensos.

Nesse sentido, o ER, com toda a sua carga histórica de confessionalidade remontando mesmo a antes do estabelecimento da educação formal brasileira, favoreceu um comportamento intolerante que podemos ver reflexos ainda hoje. Ao mesmo tempo, e considerando o aspecto ontológico da religião, sua ausência ou gestão enviesada no contexto escolar, pode ser responsável pelo incremento da violência física e simbólica $^{30}$ que caracteriza as relações pessoais e sociais contemporaneamente. Essa constatação leva em conta não um princípio que se estabeleceu para o ER como o de formação moral e ética, algo que deve ser abordado transversalmente em todo o conteúdo escolar, mas propriamente o de educação do "religioso", comum a todo indivíduo humano (necessária a redundância).

Aqui assumimos uma perspectiva necessária aos estudos de religião, e que encontra um significado mais objetivo nas aulas de ER, que é a sua consideração como algo anterior às instituições que lhe representam. A religião não estaria relacionada exclusivamente a igrejas, como apregoa o senso comum, sendo antes entendida como uma qualidade daquilo que implica uma preocupação suprema do indivíduo, não constatável na superficialidade de suas formações culturais, mas fortemente presente na profundidade da vida humana ${ }^{31}$, apreensível por meio da experiência religiosa relatada pelos indivíduos que a vivenciaram. ${ }^{32}$

Sendo algo absolutamente subjetivo, a experiência encontra objetividade a partir dos fenômenos que lhe representam mítica e ritualmente. Lidar com tais fenômenos requer um aprofundamento que permita não somente o trabalho com o visível, aquilo que é identificado pelas formas e capitais culturais, mas com sua intencionalidade composta de uma estrutura e coerência próprias. ${ }^{33}$ Essa dinâmica é a responsável

${ }^{29}$ FREIRE, Paulo. Pedagogia da autonomia: saberes necessários à prática educativa. 54. ed. Rio de Janeiro: Paz e Terra, 2016. p. 36.

${ }^{30}$ BOURDIEU, Pierre. A Economia das Trocas Simbólicas. 5. ed. São Paulo: Perspectiva, 1998.

${ }^{31}$ TILLICH, Paul. Teologia da Cultura. São Paulo: Fonte Editorial, 2009.

${ }^{32}$ GRESCHAT, Hans-Jürgen. O que é ciência da religião? São Paulo: Paulinas, 2005.

${ }^{33}$ CROATTO, José Severino. As linguagens da experiência religiosa: uma introdução à fenomenologia da religião. 3. ed. São Paulo: Paulinas, 2010. 
pela criação e pelo estabelecimento das religiões formais, como conhecemos, e da religião enquanto substância cultural presente na qualidade de suas representações formais. ${ }^{34}$

Para se verificar esse processo que como temos desenvolvido até agora se encontra apenas representado em capitais culturais, o método fenomenológico torna-se mais adequado haja vista dar conta não de suas "cascas externas" ${ }^{35}$, mas do sentido a elas intrínsecas ${ }^{36}$ Assim, a pergunta do cientista da religião (que aqui pode ser do professor de ER preocupado em elaborar um material didático adequado para os seus alunos), ao iniciar o trabalho com esse método, deve ser: "o que significam esses aspectos [capitais culturais] para os fiéis?"'37. As respostas, vindas dos próprios fiéis (alunos ou sínteses de pesquisas de ciência da religião) constituir-se-ão inicialmente em um material bruto que, trabalhado "artesanalmente" ${ }^{38}$ a partir de uma interpretação de sentidos (para o fiel), permitirão uma experiência de aprendizagem não só inovadora, dadas as atuais abordagens do ER, mas instigadora e mesmo transformadora, haja vista lidar com uma substância profundamente "susceptível de modificar a qualidade da própria existência"39.

Com essa breve discussão teórica, intentou-se tornar o objeto religioso mais amplo, podendo ser visualizado mesmo em representações não religiosamente institucionais. Contudo, sendo a religião institucional, atualmente plural e multifacetada, o lugar onde os fenômenos religiosos ocorrem mais intensamente e com maiores interpelações no espaço público, cabe a redução a essas representações, tomando-as como exemplo máximo nas abordagens pedagógicas na escola. Ademais, são elas que também dominam o debate religioso quando requeridas nas recentes discussões sobre a temática em ambientes outros. Por isso, reiterando o papel precípuo da educação escolar na preparação do educando para o exercício da cidadania ${ }^{40}$, tal objeto necessita da devida atenção escolar a fim de lhe dar o seguimento adequado para alcançar o resultado almejado pela lei.

Para tanto, requer-se do professor de ER, dada a ausência de dispositivos e elaborações didáticas fornecidas pelos sistemas de ensino, como é retratada a realidade escolar brasileira, a cuidadosa atenção às formulações trazidas pelos alunos de suas próprias realidades religiosas, uma atenção precípua em relação aos seus capitais culturais. Esse trabalho demanda um conhecimento fenomenológico das religiões representativas do campo religioso brasileiro e que, certamente, estarão minimamente presentes no contexto da sala de aula ou da escola.

\footnotetext{
${ }^{34}$ Paul Tillich assim relaciona religião e cultura: "La cultura es la forma de expresión de la religión, y la religión es la sustância (Inhalt) de la cultura" (TILLICH, 1973, p. 62).

35 GRESCHAT, 2005, p. 139.

36 CROATTO, 2010.

37 GRESCHAT, 2005, p. 80.

38 OLIVEIRA, Paulo de Salles. Metodologia das Ciências Humanas. São Paulo: HUCITEC; UNESP, 1998. p. 18.

39 ELIADE, Mircea. Origens: História e sentido na religião. Lisboa: Edições 70, 1989. p. 81.

${ }^{40}$ BRASIL, 1996.
} 
A consideração fenomenológica às religiões pretende inibir quaisquer formas de proselitismo e, consequentemente, o estabelecimento de partidarismos que acarretam dissensões e violências desde o espaço escolar, mas sem invalidar ou relativizar, mesmo que minimamente, as crenças dos alunos. Aqui se assume uma perspectiva de uma escola que valoriza a autonomia do educando ${ }^{41}$, fornecendo-lhe subsídios que irão ajudá-lo a lidar com as questões que lhe acometem no cotidiano e não as substituindo por outras, estando aí a semente das tensões atualmente verificadas quando o assunto é ER na escola.

Citando um caso afim, durante uma aula de materiais didáticos do ER, ministrada no curso de Ciências da Religião da Universidade Federal de Sergipe, uma estudante expressou sua experiência que, ao desenvolver seu estágio supervisionado em uma escola pública municipal em Aracaju, um aluno do sexto ano do ensino fundamental manifestou-se contrário à matéria de ER justificando que um dos professores que havia ministrado algumas aulas da disciplina teria afirmado que "Deus não existe", algo que teria sido ratificado por outros alunos da sala. A indagação da estudante foi sobre o que ela deveria ter feito diante de tal circunstância. Considerando a discussão aqui apresentada, a suposta afirmação do professor representa uma situação disforme ao papel educativo escolar, haja vista ser inadequado o estabelecimento de valores, sobretudo religiosos nessa perspectiva, sob quaisquer pretextos. Assim, ainda que motivado a emitir uma opinião sobre a questão da existência de Deus, sua formação deveria levá-lo a uma discussão acerca do papel do divino na experiência humana de busca de sentido, algo que difere do ponto de vista dos demais capitais culturais (formações míticas e rituais das religiões institucionais), mas que fenomenologicamente compreendem tanto a dinâmica da religião cristã como a de outras tradições religiosas, mesmo aquelas que não adotam o monoteísmo.

Esse tratamento didático e metodológico pretende um avanço epistemológico nas discussões sobre a presença do ER nas escolas, notadamente públicas, tendo em vista que a centralidade na experiência religiosa causadora de fenômenos religiosos promovedores e mantenedores das religiões não interfere na laicidade do Estado, mas educa o cidadão a lidar com essas experiências de sentido. A anulação desse processo acarreta as tensões já amplamente conhecidas e discutidas. Mas a devida atenção a ele fornece condições mais adequadas para o indivíduo vivenciar sua religiosidade sem ter de negá-la ou impô-la, sendo ambas as representações simbólicas de violência.

\section{Considerações finais}

Como é possível aos professores de ER instituírem, nos espaços escolares, princípios multiculturais para estudantes que estão no processo de socialização primária com capitais culturais familiares constituídos por uma linguagem religiosa naturalizada enquanto sistema simbólico com elementos de totalidade coerente e que absolutiza o relativo e o arbitrário? Como propor um ER para crianças e adolescentes com posse

${ }^{41}$ FREIRE, 2016. 
de capitais culturais familiares que transfiguram as instituições sociais em sobrenaturais, estruturam suas vidas a partir desses princípios e conferem às relações sociais função simbólica de conferir à ordem social seu caráter transcendente e inquestionável? Como atuar em um espaço escolar no qual a lei n ${ }^{\circ} 9.475 / 97$ proíbe o proselitismo e tenta resolver o dilema epistemológico do ER pelo comportamentalismo, como se os educandos fossem incapazes de resistir aos esforços proselitistas das denominações religiosas? Como lidar com professores e estudantes cujos capitais culturais estão articulados com nosso modelo flexível de laicidade, pautado na adoção de sistema de cooperação entre Estado e algumas igrejas, no qual não há "religião oficial", mas benevolência com algumas instituições eclesiásticas, com concordatas e acordos contratuais com a "religião pública" ou a "religião da maioria" ou a "religião civil"?

Os processos brevemente relatados envolvem diretamente os dilemas epistemológicos do ER na contemporaneidade. Diante da ausência de parâmetros ou diretrizes nacionais, da frouxidão na definição do objeto e do método para o ER, o caso estanciano, citado no início deste artigo, é típico das afirmativas de muitos professores que afirmam que não sabem "o que" ensinar (ensino das religiões ou no ensino da fé), "como" ensinar (catequético-evangelizador ou analítico-descritivo). Se não existem objetos e métodos definidos, o espaço fica aberto para práticas proselitistas e missionárias, pois falta ainda a formação epistemológica para os docentes relativos à religião em sala de aula. Em alguns sistemas de ensino são desenvolvidas diretrizes curriculares. Mas em outros não. Alguns propõem capacitação docente, outros não. Há a utilização de materiais didáticos que buscam auxiliar os docentes quanto ao "O que ensinar" e "Como ensinar". Entretanto, a plausibilidade desses materiais e suas propostas e metodologias adotadas ainda é exígua. Na sala de aula os educadores imbuídos de vontade agem deliberadamente de forma evangelizadora repondo o legado histórico da catequese. A falta significativa de formação docente e o despreparo se revelam em um tipo de formação que concede mais espaço à preocupação com a moralidade e a ética. ${ }^{42}$

Tradicionalmente os professores ministram o ER como complemento de carga horária e/ou através de seus vínculos religiosos, o que implica o reconhecimento dos seus respectivos capitais culturais. A partir desse quadro docente, as tensões observadas no espaço escolar envolviam diretamente as denúncias e reivindicações das denominações religiosas não hegemônicas, sobretudo os evangélicos, por políticas de equidade em relação aos católicos. As disputas abrangiam a busca pela capacidade de propor, deliberar e participar da execução das políticas públicas no Brasil relativas à formação e habilitação dos professores e na definição dos conteúdos ministrados no ER, principalmente em um cenário de pluralismo cristão cada vez mais evidente, de acelerado trânsito religioso de fiéis em direção aos grupos evangélicos neopentecostais, de aproximação dos agentes religiosos com os partidos políticos, da ampliação da presença de líderes religiosos no Legislativo, dos interesses pelas concessões nos mass media e parcerias com as agências governamentais nas áreas da educação.

${ }^{42}$ RODRIGUES, 2015. 
Por outro lado, essas lacunas nas reflexões teóricas, epistemológicas e metodológicas na formação dos professores possibilitam espaço para que as instituições religiosas e seus discursos proselitistas, intolerantes, fundamentalistas e exclusivistas tomem assento e proponham seus métodos. ${ }^{43}$ Isso nos remete à constituição de uma espécie de "arena religiosa" entre as secretarias de educação e os agentes religiosos que tradicionalmente atuam nesse ensino e defendem a continuidade do modelo catequético-evangelizador instituído e monopolizado pelo catolicismo.

Desde modo, assim como na Rede Municipal de Educação de Estância/SE, as questões multiculturais adquirem uma ampla dimensão, o cenário contemporâneo acha-se também marcado por antagonismos, tensões e conflitos, permeando os mais variados campos. Essas tensões e conflitos se multiplicam com interesses e mentalidades se articulando, confrontando-se ou se justapondo com visões homogêneas estáveis e permanentes sendo constantemente questionadas e demandando estratégias educacionais capazes de inibir para em seguida reverter essas dinâmicas. Pensar o ER mais constitutivamente, no sentido de dar-lhe uma epistemologia adequada e definitiva, pode auxiliar positivamente nesse processo. E as propostas aqui apresentadas buscam contribuir com o estabelecimento dessa epistemologia.

\section{Referências}

BERGER, Peter; BERGER, Brigitte. Socialização: como ser um membro da sociedade. In: FORACCHI, Marialice Mencarini; MARTINS, José de Souza. Sociologia e Sociedade: leitura de introdução à Sociologia. Rio de Janeiro: Editora LTC, 1980. p. 200-214.

BOURDIEU, Pierre. A Economia das Trocas Simbólicas. 5. ed. São Paulo: Perspectiva, 1998. . A Escola conservadora: as desigualdades frente à escola e à cultura. In: NOGUEIRA, Maria Alice; CATANI, Afrânio. Escritos de Educação: Pierre Bourdieu. 3. ed. Petrópolis: Vozes, 2001. ; PASSERON, Jean-Claude. A Reprodução: elementos para uma teoria do sistema de ensino. Petrópolis: Vozes, 2008.

BRASIL. Lei $n^{\circ}$ 9.394, de 20 de dezembro de 1996. Estabelece as diretrizes e bases da educação nacional. Brasília, 20 dez. 1996. Disponível em: <http://www.planalto.gov.br/ccivil_03/leis/ L9394.htm>. Acesso em: 05 ago. 2017.

. Resolução $n^{\circ} 7$, de 14 de dezembro de 2010. Fixa Diretrizes Curriculares Nacionais para o Ensino Fundamental de 9 (nove) anos. Brasília, 14 abr. 2010. Disponível em: <http://portal. mec.gov.br/dmdocuments/rceb007_10.pdf>. Acesso em: 31 jul. 2017.

CROATTO, José Severino. As linguagens da experiência religiosa: uma introdução à fenomenologia da religião. 3. ed. São Paulo: Paulinas, 2010.

ELIADE, Mircea. Origens: História e sentido na religião. Lisboa: Edições 70, 1989.

FREIRE, Paulo. Pedagogia da autonomia: saberes necessários à prática educativa. 54. ed. Rio de Janeiro: Paz e Terra, 2016.

GONÇALVES, Luiz Alberto Oliveira; SILVA, Petronilha Beatriz Gonçalves e. Multiculturalismo e educação: do protesto de rua a propostas e políticas. Educação e Pesquisa, São Paulo, v. 29, n. 1, p. 109-123, jan./jun. 2003.

GRESCHAT, Hans-Jürgen. O que é ciência da religião? São Paulo: Paulinas, 2005.

${ }^{43}$ RODRIGUES, 2015. 
GRIGOROWITSCHS, Tamara. O Conceito "Socialização" caiu em desuso? Uma análise dos processos de socialização na infância com base em Georg Simmel e George H. Mead. Educação e Sociedade, Campinas, v. 29, n. 102, p. 33-54, jan./abr. 2008.

JÚLIA, Dominique. A cultura escolar como objeto histórico. Revista Brasileira de História da Educação, n. 1, p. 9-43, jan./jun. 2001.

LUI, Janayna de Alencar. Educação, laicidade e religião: controvérsias sobre a implementação do ensino religioso em escolas públicas. Tese (Doutorado em Sociologia e Antropologia) - Instituto de Filosofia e Ciências Sociais da Universidade Federal do Rio de Janeiro (IFCS-UFRJ), 2011. RODRIGUES, Elisa. Formação de professores para o ensino de religião nas escolas: dilemas e perspectivas. Ciências da Religião: história e sociedade, São Paulo, v. 13, n. 2, p. 19-46, jul./ dez. 2015.

OLIVEIRA, Paulo de Salles. Metodologia das Ciências Humanas. São Paulo: HUCITEC; UNESP, 1998.

PAULY, Evaldo Luis. O dilema epistemológico do ensino religioso. Revista Brasileira de Educação, n. 27, p. 172-212, set./out./nov./dez. 2004.

TILLICH, Paul. Teologia da Cultura. São Paulo: Fonte Editorial, 2009. . Filosofia de la religión. Buenos Aires: Megápolis, 1973. 